REVISTA DE DERECHO UNED, NÚM. 11, 2012

\title{
VIOLENCIA DE GÉNERO Y EXTRATERRITORIALIDAD DE LA LEY PENAL. LA PERSECUCIÓN DE LA MUTILACIÓN GENITAL FEMENINA
}

\author{
GENDER VIOLENCE AND CRIMINAL LAW \\ EXTRATERRITORIALITY PERSECUTION OF FEMALE GENITAL \\ MUTILATION
}

\begin{abstract}
M. ${ }^{a}$ Dolores Serrano TÁrRaga
Profesora Contratada Doctora de Derecho penal y criminología. Titular acreditada. Departamento de Derecho penal y criminología. UNED
\end{abstract}

Resumen: El aumento de los flujos migratorios en las últimas décadas ha hecho que conociéramos en nuestro país y en los de nuestro entorno la mutilación genital femenina, práctica perteneciente a las tradición cultural de algunos grupos de inmigrantes, que constituye una manifestación de violencia de género, un atentado a los derechos humanos de las mujeres y que lesiona bienes jurídicos fundamentales recogidos en la Constitución. La tolerancia y el respeto a la identidad cultural de los inmigrantes tiene como límite el respeto de los derechos fundamentales, por lo que no se pueden admitir como lícitas en nuestro país la mutilación de las mujeres inmigrantes, que en la mayoría de los casos son menores de edad. Desde hace tiempo a nivel mundial se lucha para eliminar estas prácticas. Nuestro país se ha unido a esta lucha y siguiendo las recomendaciones internacionales, ha incluido el delito de mutilación genital en el Código penal y en el principio de justicia universal, en virtud de mismo, los Tribunales españoles serán competentes para juzgar las mutilaciones genitales realizadas fuera de nuestro territorio si los responsables se encuentran en España. 
Abstract: Increased migration in recent decades has made us to know in our country and in our environment female genital mutilation, a practice belonging to the cultural tradition of some immigrant groups, which are a manifestation of gender violence, a attack on the human rights of women and injured fundamental legal rights enshrined in the Constitution. Tolerance and respect for the cultural identity of immigrants is limited to the respect of fundamental rights and therefore can not be permitted in our country as lawful mutilation of immigrant women, who in most cases are lower of age. It has long worldwide are struggling to eliminate these practices. Our country has joined this struggle and following international recommendations, included the crime of female genital mutilation in the Criminal Code and the principle of universal justice, under it, the Spanish courts are competent to judge genital mutilation carried out our territory if those responsible are in Spain.

Palabras clave: Mutilación genital femenina, violencia de género, derechos humanos, extraterritorialidad de la ley penal, principio de justicia universal.

Keywords: Female genital mutilation, domestic violence, human rights, extraterritorial criminal law principle of universal justice.

Recepción original: 17/07/2012

Aceptación original: 26/07/2012

Sumario: I. Introducción; II. Mutilación Genital y Derechos Humanos; III. La Mutilación Genital Femenina como manifestación de la Violencia de Género; IV. La Mutilación Genital Femenina en la Legislación Española; IV.1. Propuestas legislativas; IV.2. Tipificación en el Código penal; IV.3. Ley Orgánica del Poder Judicial; V. Principio de Jurisdicción Universal; VI. Conclusiones.

\section{INTRODUCCIÓN}

La violencia de género es la que se ejerce contra las mujeres por razón de su sexo, por el hecho de ser mujer, violencia cuyo fundamento reside en una concepción patriarcal de la sociedad. Una manifestación de la violencia de género la constituye la mutilación genital femenina, que es un ejercicio de violencia contra las mujeres, una demostración del sometimiento que el hombre realiza sobre la mujer, que constituye un grave atentado contra los derechos humanos, porque afecta directamente a la integridad y dignidad como persona. La mutilación de los órganos genitales de las mujeres debe considerarse un trato 
«inhumano y degradante» incluido, junto a la tortura, en las prohibiciones del artículo 3 del Convenio Europeo de Derechos Humanos ${ }^{1}$. La Convención de las Naciones Unidas para la Eliminación de todas las formas de Discriminación contra la Mujer, en su artículo 2.f prevé que los Estados parte adopten medidas adecuadas, incluso de carácter legislativo, para modificar o derogar leyes, reglamentos, usos y prácticas que constituyan una discriminación contra las mujeres.

Asimismo, el Programa de Acción de la Conferencia Internacional sobre Población y Desarrollo, celebrada en El Cairo en 1994 y el Programa de Pekín de 1995, incluyen recomendaciones a los Estados a fin de erradicar las mutilaciones genitales femeninas y modificar los comportamientos sociales y culturales dirigidos a acabar con los perjuicios y prácticas lesivos para las personas.

La mutilación genital femenina constituye un problema para todos los Estados. La Organización Mundial de la Salud estima que, en el mundo, hay 130 millones de mujeres víctimas de mutilaciones genitales practicadas en nombre de la cultura y tradiciones religiosas.

En las últimas décadas la inmigración ha tenido una gran importancia en Europa y en nuestro país, con la llegada de un número considerable de inmigrantes procedentes de diferentes países, con una cultura y costumbres diferentes a la nuestra, que nos han mostrado prácticas desconocidas en España como la de la mutilación genital femenina, que atenta a los derechos humanos, por lo que se iniciaron reformas legislativas para luchar contra esta manifestación de la violencia de género.

\section{MUTILACIÓN GENITAL Y DERECHOS HUMANOS}

La mutilación genital femenina es una práctica ancestral, no es patrimonio de ninguna cultura determinada ni es un precepto religioso, como la circuncisión masculina. Se trata de una costumbre que se cree que nació en Egipto y se fue extendiendo por las comunidades tribales de muchos países africanos ${ }^{2}$. Se ha mantenido por la tradición y su práctica está muy extendida en África y en algunos países de otros continentes. Se realiza como rito de iniciación a la

${ }^{1}$ Artículo 3. Prohibición de la tortura.

Nadie podrá ser sometido a tortura ni a penas o tratos inhumanos o degradantes.

${ }^{2}$ ADAM MUÑOZ, M. ${ }^{a}$ D., La mutilación genital femenina y sus posibles soluciones desde la perspectiva del Derecho Internacional privado, Córdoba, Universidad de Córdoba, Instituto Andaluz de la Mujer, 2003, pág. 25. 
edad adulta y como signo que caracteriza a las mujeres que pertenecen a un determinado grupo.

Los Estados miembros de la Unión Europea y los países occidentales, cuyas Constituciones reconocen el derecho a la integridad personal, tanto física como psíquica, como un derecho fundamental, se han tenido que enfrentar a las prácticas de mutilaciones genitales femeninas que constituyen un atentado a los derechos fundamentales.

El mantenimiento de la diversidad cultural plantea la necesidad de conseguir una coexistencia pacífica entre la mayoría y las minorías culturales $^{3}$. Es necesaria la integración de los inmigrantes en el país de acogida, que no significa asimilación, por lo que se les reconoce su derecho a conservar su propia cultura, sus tradiciones y sus creencias religiosas. Se protege el multiculturalismo, la pluralidad cultural, pero el problema se plantea cuando las prácticas culturales entran en conflicto con los derechos humanos y los derechos civiles reconocidos en el país de acogida. El límite a la tolerancia del multiculturalismo se establece en el respeto a los derechos fundamentales de la persona ${ }^{4}$. En ningún caso el respeto a su propia cultura puede suponer la vulneración de los derechos fundamentales, reconocidos como universales, ni tampoco la infracción o vulneración de los derechos y libertades reconocidos a todos los ciudadanos en la Constitución española. Se debe respetar la diversidad cultural y la realización de las prácticas culturales propias ${ }^{5}$, siempre que no supongan una vulneración de los derechos humanos, por lo tanto, el límite al respeto a la diversidad cultural vendrá determinado por los derechos humanos y las libertades fundamentales reconocidos a todos los ciudadanos.

El relativismo cultural se alega por muchas culturas para legitimar la mutilación genital, pero esta costumbre debe ser valorada como negativa frente al concepto de derechos fundamentales ${ }^{6}$, por-

${ }^{3}$ BOËL SAMBUC, «Los peligros del relativismo cultural», en Derecho penal y pluralidad cultural, en Anuario de Derecho penal , 2006, pág. 260.

${ }^{4}$ BASILE, F. «El derecho en las sociedades multiculturales europeas: los delitos motivados por la cultura realizados por los inmigrantes» (en particular las mutilaciones genitales femeninas), en Estudios penales en Homenaje a Enrique Gimbernat, tomo II, C. García Valdés, A. Cuerda Riezu, M. Martínez Escamilla, R. Alcácer Guirao, M. Valle Mariscal de Gante (Coords), Madrid, Edisofer, 2008, págs. 1853-1854.

${ }^{5}$ En muchos casos, las personas que practican la mutilación genital no tienen conciencia de que están cometiendo un delito, porque según sus costumbres y tradiciones, es una práctica lícita, aprobada y aceptada, no consideran que constituya una lesión, un delito contra la integridad de la persona, lo que ocurre es que sus preceptos culturales no coinciden con las leyes de nuestro país y de otros países de nuestro entorno.

${ }^{6}$ ZÚNIIGA RODRÍGUEZ, L., Política criminal, Madrid, Colex, 2001, pág. 27, nota 17. 
que el respeto a los mismos debe prevalecer frente a la justificación de prácticas que los lesionan amparándose en el relativismo cultural. Este es el criterio recogido en la sentencia de la Audiencia Provincial de Teruel, de 15 de noviembre de 2011, que condenó a los padres de una menor de edad, a la que habían realizado la mutilación genital antes de haber cumplido un año. Los acusados, procedentes de Gambia, solicitaron la exclusión de la responsabilidad penal por su pertenencia a una cultura diferente a la española de la que es parte la mutilación genital femenina. No se admitió esta causa porque el "peso de la tradición» no es suficiente para fundar la exención de la responsabilidad penal, teniendo en cuenta, recoge la sentencia, lo dispuesto en el artículo 3.2 de la Ley de Extranjería. Hay que respetar las diferencias culturales de los inmigrantes pero dentro de los límites objetivos de tolerancia fijados por el derecho y los valores dominantes de la sociedad de acogida ${ }^{7}$. Si se respetan todas las costumbres de los grupos inmigrantes, amparadas por razones culturales, podrían suponer una infracción, en algunos casos de los principios de igualdad y no discriminación, como ocurre, con la mutilación genital femenina, los matrimonios forzados...El respeto de las diferencias culturales está limitado por la aplicación sin discriminación del derecho positivo a todos, mayoría y minorías. No pueden legitimarse comportamientos que cuenta con una larga tradición en su realización dentro de determinados grupos, alegando que forman parte de su cultura y que constituyen un grave atentado contra los derechos fundamentales reconocidos en normas internacionales y en las nacionales del país de acogida ${ }^{8}$. No se debe, amparándose en la tolerancia de las costumbres propias de un grupo, juzgar de forma diferente los hechos en función de la pertenencia a ciertos grupos en el marco de un procedimiento penal o del derecho de familia. Por temor de ser acusados de intolerantes, o hasta de racistas, los magistrados dudan, a veces, de aplicar la ley con el rigor necesario.

La Ley de Extranjería española reconoce la integración social de los inmigrantes o extranjeros, favorece el multiculturalismo y la integración social a través del acceso a la educación y a la cultura en España ${ }^{9}$, se incluye una cláusula de salvaguarda del orden público occidental en el art. 3.2, donde se dispone que, las normas relativas

${ }^{7}$ BOËL SAMBUC, ob. cit., pág. 260.

${ }^{8}$ BALAGUER CALLEJÓN, F. «Derechos de los extranjeros e interpretación de las normas», en M. Moya Escudero (Coord.) Comentario sistemático a la Ley de Extranjería, Granada, Comares, 2001, pág. 484.

${ }^{9}$ JIMENA QUESADA, L. «Las Administraciones públicas ante los flujos migratorios», en Multiculturalismo y movimientos migratorios, Valencia, Tirant lo Blanch, 2003, pág. 417. 
a los derechos fundamentales de los extranjeros deben interpretarse de conformidad con la Declaración Universal de 1948 y los tratados y acuerdos internacionales sobre materia de derechos humanos vigentes en España, «sin que pueda alegarse la profesión de creencias religiosas o convicciones ideológicas de signo diverso para justificar la realización de actos o conductas contrarias a las mismas».

El hecho de que la mutilación genital femenina sea una práctica tradicional, integrada en los ritos culturales en algunos países de los que son originarios los inmigrantes, no puede considerarse una justificación para no prevenir, perseguir y castigar semejante vulneración de los derechos humanos en todo el mundo, por esta razón ha sido muy importante la inclusión del delito de mutilación genital femenina en el principio de justicia universal, en virtud del mismo, en nuestro país se podrán perseguir y castigar los delitos de mutilación genital femenina si los responsables se encuentran en España.

\section{LA MUTILACIÓN GENITAL FEMENINA COMO MANIFESTA- CIÓN DE LA VIOLENCIA DE GÉNERO}

La violencia de género es aquella que se ejerce sobre las mujeres por razón de su sexo, por el hecho de ser mujer, como manifestación de la discriminación, la situación de desigualdad y las relaciones de poder de los hombres sobre las mujeres, como recoge el artículo 1 de la Ley Orgánica 1/2004, de 28 de diciembre, de Medidas de Protección Integral contra la Violencia de Género ${ }^{10}$. Una de sus manifestaciones más genuinas la constituye la mutilación genital femenina, que se practica a las mujeres pertenecientes a determinadas culturas,que las sitúa en una posición de discriminación respecto a los hombres. El delito de mutilación genital femenina constituye violencia de género ${ }^{11}$, pero no todas las mujeres del mundo tienen

${ }^{10}$ En el artículo 1 de la ley se recoge que el objeto de la ley es su aplicación a la violencia de género ejercida sobre las mujeres por parte de quienes sean o hayan sido sus cónyuges o de quienes estén o hayan estado ligados a ellas por relaciones similares de afectividad, aun sin convivencia, pero no sólo en el ámbito de las relaciones de pareja se realizan actos de violencia de género.

${ }^{11}$ Algunas leyes autonómicas de violencia de género sí que incluyen expresamente la mutilación genital femenina como una manifestación de la misma: en la Ley 5/2005, de 20 de diciembre, Integral contra la Violencia de Género de la Comunidad de Madrid; Ley 5/2008, de 24 de abril, del derecho de las mujeres a erradicar la violencia machista de Cataluña que recoge la mutilación genital femenina y también el riesgo a padecerla; Ley 13/2010, de 9 de diciembre, contra la Violencia de Género en Castilla y León, que considera violencia de género «Violencia originada por la aplicación de tradiciones culturales que atenten o vulneren los derechos humanos»; Ley 7/2007, 
la probabilidad de ser víctimas de una mutilación, sino que sólo lo pueden ser aquellas mujeres que pertenecen a culturas donde está arraigada esta práctica. En este delito concurren dos aspectos de los delitos de género: ser mujer y una mayor vulnerabilidad. Son vulnerables las mujeres de los pueblos donde está arraigada la práctica de la mutilación genital, pero no todas las mujeres. Además abundarían en su reconocimiento como delito de género razones preventivas, pues el riesgo de padecer esta conducta sólo lo tienen las mujeres, lo que vulnera el principio de igualdad. El derecho penal de género debe basarse en la protección de un nuevo bien jurídico, la igualdad $^{12}$, digno de protección por parte del derecho penal ${ }^{13}$. La mutilación conlleva un atentado a la igualdad, derecho reconocido en todas las declaraciones de derechos e instrumentos internacionales. Supone una desigualdad entre hombres y mujeres de forma flagrante, consentida y admitida. Nuestra Constitución reconoce la igualdad de todos los ciudadanos ante la ley, pero esta es una igualdad formal, que no se traduce en una igualdad real, material y efectiva, que según el artículo 9.2 de la Constitución deben promover los poderes públicos ${ }^{14}$, lo que conlleva crear políticas denominadas de discriminación positiva a favor de aquellos grupos desfavorecidos, que reciben una tutela adicional por parte del Estado ${ }^{15}$, es lo que se ha hecho con la ley de violencia de género, para eliminar las condiciones que colocan a un grupo concreto en situación de desventaja, lo que ocurre con las mujeres víctimas de violencia de género. Las mujeres que pueden ser víctimas de mutilación genital femenina en nuestro país constituyen una minoría, son extranjeras, en muchos casos menores de edad, y el Estado debe protegerlas de forma específica y especial, pues esta práctica constituye una lesión, una vulneración de los derechos fundamentales.

de 4 de abril, para la Igualdad entre Mujeres y Hombres, y de Protección contra la Violencia de Género en la Región de Murcia; Ley 16/2003, de 8 de abril, de Prevención y Protección Integral de las Mujeres contra la Violencia de Género de Canarias; Ley de Cantabria 1/2004, de 1 de abril, Integral para la Prevención de la Violencia Contra las Mujeres y la Protección a sus Víctimas; Ley 4/2007, de 22 de marzo, de Prevención y Protección Integral a las Mujeres Víctimas de Violencia en Aragón.

${ }^{12}$ ALAMO ÁLONSO, M., "Protección penal de la igualdad y derecho penal de género», en Reforma del Código penal. Respuestas para una sociedad del siglo XXI, I. Fco. Benítez Ortúzar, Madrid, Dykinson, 2008, pág. 89.

${ }^{13}$ BOLDOVA PASAMAR, M.A.,/RUEDA MARTÍN, Mª.A., «La discriminación positiva de la mujer en el ámbito penal», en La Ley, n. ${ }^{\circ}$ 6146, 14 de diciembre de 2004, pág. 5

${ }^{14}$ FERRAJOLI, «La differenza sessuale e le garanzie dell'ugaglianza», en Democrazia e Diritto, n. ${ }^{\circ}$ 2, 1993, pág. 65.

${ }^{15}$ REY MARTÍNEZ, F., El derecho fundamental a no ser discriminado por razón de género, Madrid, McGraw-Hill, 1995, pág. 59. 
El mantenimiento de las prácticas de mutilación genital femenina supone la materialización de las desigualdades que a lo largo de la historia han sufrido las mujeres por su condición y su pertenencia a culturas que mantienen estas desigualdades y una concepción patriarcal de la sociedad que no respeta los derechos humanos, amparándose en el mantenimiento de unas tradiciones culturales propias y características de la idiosincrasia de su pueblo. En la mutilación genital femenina se convierte una tradición cultural en un conflicto de género, reflejo de la sociedad patriarcal, porque si bien la realizan las mujeres, los hombres pueden ser inductores, cooperadores o cómplices, hay que tener en cuenta que lo hacen para mantener las tradiciones en las que se incluye la concepción social de la mujer, transmitida de forma histórica, como sometida a su marido. Los Estados que no comparten estas pautas culturales deben educar a estos pueblos para que las tradiciones se adapten a los derechos humanos, que se mantengan aquellas que no los vulneran, por eso los países occidentales deben luchar por la extensión de los derechos humanos a todos los ciudadanos y la desaparición de la discriminación por razón de sexo o género.

En la mutilación genital femenina se aprecia, también, un ataque a la dignidad de las mujeres,estrechamente relacionada con la igualdad, reconocida en la Constitución como un derecho fundamental ${ }^{16}$, así como un atentado contra la libertad,la integridad física, la salud, el derecho a su libertad sexual, a disponer de su propio cuerpo, a la maternidad y al desarrollo de su personalidad. Esta práctica atentaría contra el derecho constitucional a no ser sometida a trato inhumano o degradante por el hecho de ser mujer.

Por la conculcación de estos derechos en aquellos países donde la tradición impone esta practica y constituir una manifestación de la violencia de género, se inicia la lucha contra la misma por organismos internacionales, las Naciones Unidas y la Unión Europea. Lucha que se ha recrudecido en los últimos años por el aumento de los flujos migratorios, que han convertido la mutilación genital femenina en un problema global, porque ha traspasado las fronteras de los países en los que estaba arraigada por razones culturales, y quiere practicarse en los países de acogida, a pesar de estar prohibida por la legislación, y para ello alegan que estas prácticas constituyen parte de su cultura.

${ }^{16}$ CASTELLÓ NICÁS, N. «Problemática sobre la concreción del bien jurídico protegido», en Estudios penales sobre violencia doméstica, Lorenzo Morillas Cueva (Coord), Madrid, editoriales de Derecho Reunidas, 2002, pág. 71. 
La lucha por los derechos de la mujer puede verse afectada y originar un retroceso en los logros conseguidos, si se admiten prácticas culturales, como la mutilación genital femenina, en mujeres inmigrantes, que están prohibidas y son rechazadas en los países de acogida, tanto desde un punto de vista ético como jurídico ${ }^{17}$. La lucha contra la mutilación genital de las mujeres se inserta en la propia lucha por el reconocimiento de la igualdad de la mujer; igualdad en lo relativo a sus derechos y a su dignidad como persona.

\section{LA MUTILACIÓN GENITAL FEMENINA EN LA LEGISLACIÓN ESPAÑOLA}

El derecho penal no ha permanecido ajeno a la nueva realidad que ha supuesto en nuestro país la llegada de inmigrantes, con su propia tradicional cultural y sus costumbres, que ha motivado, en algunos casos, la inclusión de nuevos tipos penales, que tipifican como delitos comportamientos desconocidos en nuestra cultura. Esto ha ocurrido con la inclusión en nuestro ordenamiento jurídico penal del delito de mutilación genital femenina que obedece, fundamentalmente, a dos razones: por una parte, a las recomendaciones recogidas en documentos internacionales sobre la necesidad de incluir en las legislaciones penales el delito de mutilación genital femenina, que tiene su antecedente en los movimientos de lucha, a nivel internacional, contra estas prácticas; y por otra parte, la conciencia de que la mutilación genital femenina constituye una manifestación de la violencia de género, ya que las mismas se realizan a las mujeres por el hecho de ser mujeres. Este delito supone un atentado contra la dignidad de la mujer a la vez que vulnera los derechos fundamentales.

\section{IV.1. Propuestas legislativas}

En las primeras proposiciones no de Ley presentadas en el Parlamento ya se apreciaba como un problema para luchar contra la mutilación genital femenina, la dificultad de perseguir en nuestro país los hechos que se descubrían, porque las prácticas se habían realizado en el país de origen o en otro diferente al nuestro, y España no tenía competencia para juzgar estos hechos.

${ }^{17}$ MARCOS DEL CANO, A. $\mathrm{M}^{\mathrm{a}}$, «El proceso de integración de la inmigración: luces y sombras», en Marcos del Cano, A. $\mathrm{M}^{\mathrm{a}}$ (Coord.) Inmigración, multiculturalismo y derechos humanos, Valencia, Tirant lo Blanch-UNED, 2009, pág. 128. 
En la primera proposición de Ley presentada en el Congreso para incluir en nuestro ordenamiento jurídico el delito de mutilación genital ya se contemplaba la necesidad de reformar el Código penal y la Ley Orgánica del Poder Judicial, para ampliar la extraterritorialidad de la ley penal española, para que nuestra legislación fuera más eficaz en la persecución de los casos de mutilación genital femenina.

El Grupo Parlamentario Mixto presentó el 18 de mayo de 2001 una Proposición de Ley de modificación de la Ley Orgánica 6/1985, del Poder Judicial, y de la Ley Orgánica 10/1995, del Código Penal. Esta Proposición de Ley fue retirada el día 25 de junio de 2001, a favor de la enmienda transaccional firmada por los otros grupos a la que se adhirieron ${ }^{18}$.

En el texto transaccional acordado por todos los partidos que presentaron las Proposiciones no de Ley, se reconoce, por una parte, en relación al derecho penal sustantivo, que no hay duda en considerar que la mutilación genital femenina está incluida en el artículo 149 del Código penal, tipificada como lesión grave, no obstante, contempla la posibilidad de que en la comisión técnica se valore la conveniencia de una mención más explicita para garantizar su correcta conceptualización penal, para impedir que estas lesiones puedan ser consideradas lesiones menos graves. Y por otra parte, se insta a la comisión técnica, encargada de revisar el tema de las penas, llevar a cabo un análisis de las posibilidades de la legislación española, para que la mutilación genital femenina se sancione adecuadamente, con independencia del lugar donde se haya efectuado y siempre que el responsable se encuentre en España. Pero debe meditarse la extensión del principio de justicia universal a la mutilación genital femenina, aún reconociendo la necesidad que hay que hacerlo debido a la impunidad de estas prácticas en determinados países, la aplicación de este principio requiere examinar las penas con las que se castiga la mutilación genital en los países de nuestro entorno, para que no existan grandes diferencias en la penalidad ${ }^{19}$. En este texto se recogía que la lucha contra la mutilación genital femenina no se limita a su castigo penal, sino que debe acudirse a programas de ayuda a las mujeres, dirigidos a concienciar a la población que esas prácticas son contrarias a los derechos fundamentales, y a medidas de prevención e información a la población.

${ }^{18}$ Cortes Generales, Diario de Sesiones del Congreso de los Diputados, 19 de junio de 2001, núm. 92.

${ }^{19}$ Cortes Generales, Diario de Sesiones del Congreso de los Diputados, 19 de junio de 2001, Núm. 92. 
El 1 de junio de 2001 el Partido Socialista presentó en el Senado una Proposición de Ley para la reforma del artículo 23, punto 4, de la Ley Orgánica 6/1985, de 1 de julio, del Poder Judicial, y del artículo 149 de la Ley Orgánica 10/1995, de 23 de noviembre, del Código Penal, a fin de garantizar la represión efectiva en España de la mutilación genital femenina. En esta proposición se plantean dos modificaciones, por una parte, la inclusión expresa de la mención a la mutilación genital femenina en el artículo 149 del Código penal, para aumentar la seguridad jurídica y unificar la interpretación de los Tribunales en el sentido de calificar siempre como grave deformidad o mutilación de un órgano principal las mutilaciones genitales femeninas, y por otra, la modificación del artículo 23, punto 4 de la Ley Orgánica del Poder Judicial, para incluir la mutilación genital femenina en el principio de justicia universal, siempre que las personas responsables se encuentren en nuestro país ${ }^{20}$. Se recogían en esta propuesta las opiniones de Jueces, Magistrados y Fiscales sobre la necesidad de reformar la legislación española para poder perseguir y castigar el delito de mutilación genital femenina cometido fuera de nuestras fronteras, que en algunos casos se había gestado en España ${ }^{21}$. Esta Proposición de Ley se discutió en la Sesión del Pleno del Senado el día 21 de junio de 2001, donde se aprueba el primer artículo de la propuesta, referido a la reforma del artículo 149 del Código penal, y se rechaza el segundo relativo a la reforma de la Ley Orgánica del Poder Judicial, por lo que también se modifica el título de la proposición de Ley ${ }^{22}$, que fue remitida al Congreso de los Diputados el día 19 de julio de 2001, bajo el nuevo título: Reforma del artículo 149 de la Ley Orgánica 10/1995, de 23 de noviembre, del Código Penal, a fin de introducir una cláusula interpretativa sobre la represión de la mutilación genital femenina ${ }^{23}$. Esta ley no llegó a aprobarse.

\section{IV.2. Tipificación en el Código penal}

La Ley Orgánica 11/2003, de 29 de septiembre, de medidas concretas en materia de seguridad ciudadana, violencia doméstica e

${ }^{20}$ Boletín Oficial de las Cortes Generales, BOCG, Senado, Serie III A, 1 de junio de 2001, Núm. 14 (a)

${ }^{21}$ ROPERO CARRASCO, J. «El derecho penal ante la mutilación genital femenina», en Revista La Ley, 26 de septiembre de 2001, pág. 1396.

${ }^{22}$ Cortes Generales, Diario de Sesiones del Senado, año 2001, VII Legislatura, Núm. 52, 21 de junio de 2001.

${ }^{23}$ Boletín Oficial de las Cortes Generales, BOCG, Congreso de los Diputados, serie B, Núm. 161-1, 23 de julio de 2001. 
integración social de los extranjeros, introduce en el Código penal expresamente, el delito de mutilación genital femenina. En la Exposición de Motivos, reconoce «la existencia de formas delictivas surgidas de prácticas contrarias a nuestro ordenamiento jurídico, así como que con la integración social de los extranjeros en España, aparecen nuevas realidades a las que el ordenamiento debe dar adecuada respuesta. Así, como novedad igualmente reseñable, se tipifica el delito de mutilación genital o ablación. Y ello porque la mutilación genital de mujeres y niñas es una práctica que debe combatirse con la máxima firmeza, sin que pueda en absoluto justificarse por razones pretendidamente religiosas o culturales. Esta reforma ya había sido planteada en el seno de las Cortes a través de una proposición de ley que pretendía introducir una cláusula interpretativa sobre la represión de la mutilación genital femenina».

Se añade al artículo 149 del Código Penal un nuevo apartado, el número $2^{24}$, donde se castiga la mutilación genital, en cualquiera de sus manifestaciones, con la pena de prisión de seis a doce años. Si la víctima fuera menor de edad o incapaz, se aplicará la pena de inhabilitación especial para el ejercicio de la patria potestad, si el juez lo estima adecuado al interés del menor. Con esta medida se quiere proteger a la víctima, puesto que, en la mayoría de las ocasiones, son los padres o familiares directos de la víctima quienes la obligan a someterse a la mutilación.

Una vez que el legislador español recoge en el código penal el delito de mutilación genital, se da cuenta que esta inclusión no es suficiente para perseguir y castigar estas prácticas, porque los hechos, con frecuencia, se realizan fuera de España. Cuando eran descubiertos casos de mutilación genital, los sujetos responsables decían que la habían practicado en su país de origen, durante un viaje o con ocasión de las vacaciones. En virtud del principio de territorialidad, la ley penal española sólo se podía aplicar a los españoles y extranjeros que hubieran cometido los hechos en España. Para que la ley española fuera eficaz para lograr su objetivo, era necesario ampliar la eficacia de la ley penal en el espacio, en virtud de los principios de interés real y de justicia universal, para aplicar la ley penal española a hechos cometidos fuera del

\footnotetext{
${ }^{24}$ Artículo 149 del Código penal: «1. El que causara a otro, por cualquier medio o procedimiento, la pérdida o la inutilidad de un órgano o miembro principal, o de un sentido, la impotencia, la esterilidad, una grave deformidad, o una grave enfermedad somática o psíquica, será castigado con la pena de prisión de seis a 12 años.

2. El que causara a otro una mutilación genital en cualquiera de sus manifestaciones será castigado con la pena de prisión de seis a 12 años.

Si la víctima fuera menor o incapaz, será aplicable la pena de inhabilitación especial para el ejercicio de la patria potestad, tutela, curatela, guarda o acogimiento por tiempo de cuatro a 10 años, si el juez lo estima adecuado al interés del menor o incapaz».
} 
territorio español. A pesar de los empeños de los Fiscales por perseguir estos hechos, la ley española no se podía aplicar para castigar las mutilaciones genitales cometidas por un extranjero en el extranjero. El Partido Socialista presentó en el Senado una proposición de ley, que recogía las opiniones manifestadas por Jueces, Magistrados y Fiscales sobre la necesidad de reformar la legislación española para poder perseguir y castigar el delito de mutilación genital femenina cometido fuera de nuestras fronteras y que en algunos casos se había gestado en España ${ }^{25}$. Los tribunales españoles continuaron debatiendo si era posible castigar en nuestro país los delitos de mutilación genital realizados a menores cuando éstas iban a pasar las vacaciones a sus lugares de origen, para lo que planteaban diversas soluciones, pretendiendo castigar estos hechos como actos preparatorios, al entender que la preparación del delito se había iniciado en nuestro país.

Para perseguir los delitos en virtud del principio de justicia universal en España, el legislador ha debido de incluirlos en una ley española, que establece el ámbito de competencia de los tribunales españoles para juzgar los delitos concretos ${ }^{26}$. La solución estaba en modificar la Ley Orgánica del Poder Judicial para incluir el delito de mutilación genital en el principio de justicia universal, principio que se ha aplicado desde sus inicios a delitos contra la mujer, como era la trata de blancas, que incluía el tráfico de mujeres para dedicarlas a la prostitución. La LOPJ, en su redacción de 1985, en el artículo 23.4. e) Los relativos a la prostitución, cuya redacción se modificó por Ley orgánica 11/1999, de 30 de abril, de modificación del Título VIII del Libro II del Código Penal, aprobado por Ley Orgánica 10/1995, de 23 de noviembre, quedando como sigue: Los delitos relativos a la prostitución y los de corrupción de menores o incapaces ${ }^{27}$.Hasta que no se incluye el delito en la LOPJ en la reforma del 2005, no se podían perseguir en España las conductas de mutilación genital femenina realizadas fuera de nuestro país.

\section{IV.3. Ley Orgánica del Poder Judicial}

La Ley Orgánica 3/2005, de 8 de julio, de modificación de la Ley Orgánica 6/1985, de 1 de julio, del Poder Judicial, para perseguir extraterritorialmente la práctica de la mutilación genital femenina, en

25 ROPERO CARRASCO, J., ob. cit., pág. 1396.

${ }^{26}$ GIL GIL, A. Bases para la persecución penal de crímenes internacionales en España, Granada, Comares, 2006, pág. 65.

27 Ley Orgánica 11/1999, de 30 de abril, Disposición final única, 2. «Se modifica el apartado 4, punto e, del artículo 23 de la mencionada Ley Orgánica del Poder Judicial, que tendrá la siguiente redacción: Los delitos relativos a la prostitución y los de corrupción de menores o incapaces». 
su Exposición de Motivos recoge que la mutilación genital femenina constituye un grave atentado contra los derechos humanos, es un ejercicio de violencia contra las mujeres que afecta directamente a su integridad como personas. La mutilación de los órganos genitales de las niñas y las jóvenes debe considerarse un trato «inhumano y degradante» incluido, junto a la tortura, en las prohibiciones del artículo 3 del Convenio Europeo de Derechos Humanos.

Los Estados miembros de la Unión Europea, cuyas Constituciones reconocen el derecho a la integridad personal, tanto física como mental, como un derecho fundamental, se han enfrentado a un fenómeno de exportación de la práctica de mutilaciones genitales femeninas debido a la inmigración de personas procedentes de países donde estas prácticas constituyen una costumbre tradicional aún en vigor.

El hecho de que las mutilaciones sexuales sean una práctica tradicional en algunos países de los que son originarios los inmigrantes en los países de la Unión Europea, no puede considerarse una justificación para no prevenir, perseguir y castigar semejante vulneración de los derechos humanos.

En esta línea se inscribe la presente Ley Orgánica al posibilitar la persecución extraterritorial de la práctica de la mutilación genital femenina cuando la comisión del delito se realiza en el extranjero, como sucede en la mayor parte de los casos, aprovechando viajes o estancias en los países de origen de quienes se encuentran en nuestro país.

Se añade un nuevo epígrafe g) al apartado 4 del artículo 23 de la Ley Orgánica 6/1985, de 1 de julio, del Poder Judicial, donde se recoge la mutilación genital femenina ${ }^{28}$.

En Italia, la ley de 9 de enero de 2006 introdujo el delito de mutilación genital femenina en el código penal y también preveía el castigo de la misma realizada en otro país ${ }^{29}$.

${ }^{28}$ Artículo 23.4 de la Ley Orgánica 6/1985, de 1 de julio, del Poder Judicial: Igualmente será competente la jurisdicción española para conocer de los hechos cometidos por españoles o extranjeros fuera del territorio nacional susceptibles de tipificarse, según la ley penal española, como alguno de los siguientes delitos:

a) Genocidio.

b) Terrorismo.

c) Piratería y apoderamiento ilícito de aeronaves.

d) Falsificación de moneda extranjera.

e) Los delitos relativos a la prostitución y los de corrupción de menores o incapaces.

f) Tráfico ilegal de drogas psicotrópicas, tóxicas y estupefacientes.

g) Los relativos a la mutilación genital femenina, siempre que los responsables se encuentren en España.

h) Y cualquier otro que, según los tratados o convenios internacionales, deba ser perseguido en España.

${ }^{29}$ Artículo 583 bis del Código penal italiano, en su último párrafo recoge que las 


\section{PRINCIPIO DE JURISDICCIÓN UNIVERSAL}

El principio general de la aplicación de la ley penal en el espacio es el principio de territorialidad, se aplica la ley del país donde se ha cometido el delito,tanto a nacionales como a extranjeros, que supone el ejercicio de la soberanía del Estado, en su más genuina expresión, al aplicar el ius puniendi. El principio de justicia universal supone una excepción al principio de territorialidad en la aplicación de la ley penal. Tiene carácter subsidiario respecto al principio de territorialidad, pues el principio de jurisdicción universal se alegará cuando los órganos competentes para juzgar el delito en el país que se cometió no inicien su persecución ${ }^{30}$. Después de la Segunda Guerra Mundial se consolida la aceptación de este principio por el Derecho Internacional, en el que se incluían los crímenes más graves, como los delitos de agresión, genocidio, crímenes contra la humanidad y crímenes de guerra. Tras la creación de los Estatutos de los Tribunales penales internacionales ad hoc y del Estatuto de Roma, se deduce la existencia de una opinio iuris sobre el carácter internacional de estos crímenes y la conciencia de que afectan a intereses esenciales de la Comunidad internacional en su conjunto, por lo que cualquier país tiene competencia para juzgarlos ${ }^{31}$.

El Instituto de Derecho Internacional, en Resolución dada en Cracovia el 26 de agosto de 2005, define la Jurisdicción universal como sigue: "La competencia de un Estado para perseguir, y en su caso ser declarados culpables, castigar a presuntos responsables, independientemente del lugar de comisión del delito y sin consideración a vínculo alguno de nacionalidad activa o pasiva u otros criterios de jurisdicción reconocidos por la Ley internacional». El principio de jurisdicción universal es un criterio de jurisdicción que atribuye competencia a los tribunales de un Estado para enjuiciar delitos cometidos en el extranjero por extranjeros, en los casos en los que esos delitos no se consideran una amenaza para los intereses

disposiciones del presente artículo también serán aplicables cuando el hecho se haya realizado en el extranjero por un ciudadano italiano o extranjero residente en Italia. En este caso, el infractor será sancionado, a petición del Ministro de Justicia.

${ }^{30}$ GARCÍA SÁNCHEZ, B., "El principio de justicia universal en el ordenamiento interno e internacional», en Revista de Derecho penal y Criminología, segunda época, n. ${ }^{\circ} 2$ extraordinario, 2004, pág. 246.

${ }^{31}$ ORIHUELA CALATAYUD, E. «Aplicación del Derecho Internacional Humanitario por las jurisdicciones nacionales», en F.J. QUEL LÓPEZ, Creación de una jurisdicción penal internacional, Colección Escuela Diplomática, núm. 4, Madrid, 2000, pág. 252.

SÁNCHEZ LEGIDO, A. Jurisdicción universal penal y Derecho Internacional, Valencia, Tirant lo Blanch, 2004, pág. 141-142. 
del Estado en el que se han cometido ${ }^{32}$, razón por la que no inicia su persecución y castigo.

El fundamento del principio de jurisdicción universal está en la existencia de delitos que afectan a los intereses de la Comunidad internacional. Este principio reconoce el interés que todos los Estados tienen en evitar la impunidad de los delitos más graves, que lesionan bienes jurídicos supranacionales y que atacan a los derechos fundamentales $^{33}$, que en muchos casos, un Estado sólo de forma aislada no puede perseguir, como ocurre en la mutilación genital femenina, que es necesario una lucha mundial para terminar con estas prácticas. En el principio de justicia universal se incluyen delitos que afectan a toda la humanidad ${ }^{34}$, o a una gran parte de ella, que atentan contra la paz y seguridad de la comunidad internacional y son rechazados mundialmente ${ }^{35}$.El principio de jurisdicción universal ejerce una función de prevención, quiere evitar el ataque a bienes jurídicos supranacionales, y la comisión de delitos graves en la comunidad internacional.

En nuestro país, los delitos perseguibles en virtud del principio de justicia universal, se recogen en el artículo 23.4 de la Ley Orgánica del Poder Judicial, proceden de acuerdos internacionales, de Convenios o Tratados entre distintos Estados ${ }^{36}$.

La primera característica que fundamenta el principio de jurisdicción universal es que los delitos incluidos en el mismo tienen naturaleza internacional. Con la tipificación de estas conductas se quiere proteger bienes jurídicos de carácter internacional o universal, reconocidos y amparados por la Comunidad Internacional y por cada uno de los Estados en particular, por esta razón, los Estados están interesados en enjuiciarlos, y este principio les reconoce legitimidad para hacerlo, porque también se lesionan sus intereses, y además hay que tener en cuenta que estos delitos, o las personas que los realizan, no se circunscriben a un territorio nacional, en muchos casos, su realización es a nivel internacional. La segunda nota

32 CARPIO DELGADO, J., «El principio de justicia universal en España tras la reforma de 2009», en La Ley, n. ${ }^{\circ} 7307,2009$, pág. 3.

${ }^{33}$ OLLÉ SESÉ, M. y LAMARCA PÉREZ, C. «La reforma del principio de Justicia Universal», en La Ley Penal, n. ${ }^{\circ}$ 83, 2011, pág. 4.

${ }^{34}$ BUJOSA VADELL, L.M. «En torno a la reforma del principio de justicia universal en la Jurisdicción española», en La Ley, N. ${ }^{\circ} 7298,2009$, pág. 1.

35 TRILLO NAVARRO, J.P., «Jurisdicción universal, menores y ablación»: el nuevo artículo 23.4g) LOPJ, en La Ley, $n .{ }^{\circ}$ 6354, 2005, pág. 7.

36 GARCÍA SÁNCHEZ, B. Límites a la ley penal en el espacio, Barcelona, Atelier, 2004, pág. 149. 
característica de este principio esta en la solidaridad internacional entre los Estados por defender y proteger intereses internacionales o bienes jurídicos supranacionales o universales. Al no existir un derecho penal internacional donde se recojan estos delitos ni unos tribunales internacionales que apliquen ese derecho, deben hacerlo los Estados, para que estos delitos no queden impunes. En este punto ha supuesto un avance importantísimo el Estatuto de Roma crea la Corte Penal Internacional, donde se recogen los delitos que son de su competencia, entre los que no figura la mutilación genital femenina. Pero la Corte Penal Internacional no excluye la competencia de los Estados Partes, sino que es complementaria. Y la tercera característica es la lesión de bienes jurídicos de carácter internacional o supranacional, que en algunos casos son violados por los propios Estados y ello hace necesario la existencia de este principio, para que no queden impunes y otros Estados puedan iniciar su persecución y castigo. En el caso de la mutilación genital femenina, los Estados en los que estas prácticas están arraigadas por formar parte de sus tradiciones culturales, son toleradas, no inician su persecución, a pesar de que constituyen una lesión y un atentado contra los derechos humanos, que de no existir el principio de justicia universal, quedarían impunes, si el Estado del lugar de comisión del delito no inicia su persecución.

Es fundamental que si se ha iniciado una lucha a nivel internacional contra la mutilación genital femenina por considerarla una practica contraria a los derechos humanos, que no puede tolerarse amparándose en los derechos de las minorías a su identidad cultural, identidad que debe mantenerse y respetarse siempre que no vulnere los derechos humanos. Por tanto, es lógico y era necesario su inclusión en el principio de justicia universal, extendiendo la competencia para perseguir este delito a cualquier Estado, con independencia del lugar donde se hubiera cometido el delito.

La modificación en el año 2005 del principio de justicia universal en nuestro país y la inclusión en el mismo del delito de mutilación genital femenina se inserta en la lucha más eficaz contra esta práctica y contra la violencia de género. Esta introducción de la mutilación genital femenina en el principio de jurisdicción universal, supone la aplicación extraterritorial de la ley penal, cuya finalidad es la protección de los derechos fundamentales, la integridad física y psíquica, la dignidad, la igualdad, la no discriminación y la libertad de la mujer, bienes jurídicos amparados por el derecho penal, en los casos en los que estas conductas no sean constitutivas de delito en el país en el que se realizaron, o porque, a pesar de estar castigada 
como delito en muchos de los países en los que se lleva a cabo, la toleran y no están interesados en su persecución, porque consideran que la mutilación genital es una manifestación de sus tradiciones culturales. Si el país donde se ha realizado la mutilación genital femenina no tiene interés en perseguirla, en muchos casos se debe a que este comportamiento no crea alarma social, porque se encuentra dentro de sus prácticas culturales, como no se aplica el principio de territorialidad de la ley penal, se aplica, subsidiariamente el principio de justicia universal, y cualquier país podría perseguir este delito si se encuentra incluido en este principio para que no quedara impune, como es el caso de España, que puede perseguir y castigar a los autores de este delito. Y aunque en los países donde se lleva a cabo la mutilación genital no crea alarma social, si la crea en la comunidad internacional, que rechaza estas prácticas porque vulneran los derechos humanos y constituye violencia de género.

La aplicación del principio de jurisdicción universal al delito de mutilación genital femenina se justificaría porque las víctimas siempre son mujeres y en muchos casos se trata de menores de edad, por lo que son especialmente vulnerables, por ser menores y por razón de género. Los mandatos de Derecho internacional de no impunidad y de defensa de las víctimas permite, en virtud del principio de jurisdicción universal, perseguir los delitos de mutilación genital cometidos en el territorio de otros Estados, y aplicar la ley penal española a estos supuestos. Es imprescindible la aplicación y mantenimiento de este principio en las legislaciones de los países, como una forma de lucha contra la violencia de género, para la protección de las menores y para evitar la vulneración de los derechos humanos de las mujeres inmigrantes. Este delito debe incluirse en el principio de justicia universal porque afecta a intereses de la Comunidad Internacional, porque esta práctica se ha ido extendiendo, por los movimientos migratorios, a países donde antes nunca se había realizado, lo que ha servido para concienciar a la Comunidad Internacional de que la mutilación genital femenina constituye un trato inhumano y degradante para las mujeres, que lesiona sus derechos fundamentales.

La Ley 3/2005, de 8 de julio, de modificación de la Ley Orgánica 6/1985, de 1 de julio, del Poder Judicial, para perseguir extraterritorialmente la práctica de la mutilación genital femenina, permite que la jurisdicción española conozca de aquellos hechos cometidos por españoles o extranjeros, fuera del territorio nacional, siempre que, según la ley penal española, dichos hechos sean constitutivos de determinados delitos; entre ellos se incluye la mutilación genital femenina, de la que conocerán los tribunales españoles, siempre que los res- 
ponsables se encuentren en España. Este requisito no se exigía en los otros delitos contemplados en la Ley dentro del principio de justicia universal. Hay que tener en cuenta, que esta introducción tiene lugar después de dictarse la sentencia del caso Guatemala, en la que el Tribunal Supremo estableció la limitación del principio de jurisdicción universal a los supuestos en los que los sujetos o responsables del delito perseguido se encontraran en España ${ }^{37}$. Esta modificación en la jurisprudencia del Tribunal Supremo en el ámbito de aplicación del principio de jurisdicción universal, tuvo su influencia y reflejo en la introducción del delito de mutilación genital femenina, que es el único que lo recoge, hasta el año 2009. La Ley Orgánica 1/2009, de 3 de noviembre, complementaria de la Ley de reforma de la legislación procesal para la implantación de la nueva Oficina judicial, por la que se modifica la Ley Orgánica 6/1985, de 1 de julio, del Poder Judicial, modifica el principio de jurisdicción universal, limitando la aplicación de este principio en nuestro país, de tal forma que los Tribunales españoles podrán conocer, en virtud del principio de justicia universal, los delitos recogidos en el artículo 23.4 de la Ley Orgánica del Poder Judicial, cometidos fuera del territorio nacional, si se acredita que los presuntos responsables se encuentran en España, requisito que se extiende a todos los delitos incluidos en el principio de justicia universal y que con anterioridad a esta reforma sólo se exigía en el delito de mutilación genital femenina; o bien que existan víctimas de nacionalidad española, o que se acredite un vínculo de conexión relevante con España, y en todo caso es necesario, para que los Tribunales puedan ejercer su competencia, que no se haya iniciado un procedimiento en otro país competente o en el seno de un Tribunal Internacional. Todo ello sin perjuicio de que puedan disponer los tratados y convenios internacionales suscritos por España ${ }^{38}$.

Es importante la inclusión del delito de mutilación genital femenina en el principio de justicia universal porque los Estados en los que se realiza no tienen interés en su persecución, por considerarla

37 En la reforma de la LOPJ de 2005 se incluye en el principio de jurisdicción universal el delito de mutilación genital femenina siempre que el responsable se encuentre en España, requisito que no se exige en los otros supuestos. Hay que tener en cuenta, que esta introducción se realiza después de la sentencia del caso Guatemala, en la que el TS estableció la limitación del principio de jurisdicción universal a los supuestos en los que los sujetos o responsables del delito perseguido se encontraran en España. Esta modificación en la jurisprudencia del TS tuvo su influencia y reflejo en la introducción del delito de mutilación genital femenina, que es el único que lo recoge, hasta el año 2009, que se produce la modificación del principio limitando la aplicación del principio de jurisdicción universal en nuestro país en los casos en los que se establece en la LOPJ, como ocurre en otros muchos países.

${ }^{38}$ Artículo 23.4 de la Ley Orgánica del Poder Judicial. 
una práctica cultural, que no despierta alarma social entre la población porque no se tiene conciencia de estar atentando a los derechos humanos y fundamentales de las mujeres, sino que por el contrario, consideran que es necesaria su práctica en cuanto que refuerza el sentimiento de pertenencia al grupo. La introducción de la mutilación genital femenina dentro del principio de justicia universal implica que, cuando el Fiscal tenga conocimiento de la comisión de este delito aunque no se haya realizado en España, como es perseguible por el principio de justicia universal a partir del año 2005, tiene la obligación de acusar, y mucho más si se trata de menores, en cuyo caso se añade otra obligación a la de acusar y es la protección de las menores.

Lo cierto es que a pesar de haberse tipificado como delito la mutilación genital femenina e incluido en el principio de justicia universal, para que los tribunales españoles sean competentes para juzgar a la persona o personas que hayan cometido el delito fuera de España y se encuentren en nuestro país, ha habido muy pocas condenas, por las dificultades que presenta el conocimiento y la averiguación de los hechos, que permanecen en secreto entre los miembros de la comunidad emigrante donde se han realizado. Hay que tener en cuenta que para luchar contra estas prácticas a veces el recurso al ordenamiento jurídico penal no es el más eficaz, de tal forma, que puede considerarse que la tipificación del delito de mutilación genital femenina debe ser calificado como derecho penal simbólico ${ }^{39}$, que tiene el peligro de contemplarse como una expresión del paternalismo estatal, que perpetúa la imagen de la mujer como ser débil y necesitado de protección ${ }^{40}$. Una prueba evidente de la relatividad que comporta el desarrollo de políticas legislativas de carácter penal es el hecho de que la mutilación genital femenina se encuentra también legalmente prohibida y tipificada penalmente en gran parte de los Estados en los que su realización está muy extendida.

No obstante, a pesar de que la inclusión en el código penal de tipos por razón de discriminación, como es el caso de la mutilación genital femenina, por razón de género o sexo, cumple una función simbólica ${ }^{41}$, lo que se pretende es llamar la atención sobre la situación de determinados grupos de mujeres que sufren las mutilaciones

${ }^{39}$ MESTRE DELGADO, E., «La reforma permanente como (mala) técnica legislativa en el Derecho Penal», en La Ley Penal, n. ${ }^{\circ} 1,2004$, pág. 14.

${ }^{40}$ LAURENZO COPELLO, P., «La discriminación por razón de sexo en la legislación penal», en Jueces para la Democracia, 34, 1999, págs. 21 y ss.

${ }^{41}$ CRUZ BLANCA, M. ${ }^{a}$ J., "Derecho penal y discriminación por razón de sexo. La violencia doméstica en la codificación penal», en Estudios penales sobre violencia doméstica, Lorenzo Morillas Cueva (Coord), editoriales de Derecho Reunidas, Madrid, 2002, pág. 41. 
genitales por razón de género, lo que demuestra la pervivencia en la sociedad de estructuras patriarcales, de sometimiento de la mujer al hombre, y cuya finalidad es eliminar estas prácticas de la sociedad, aún siendo conscientes de la poca o nula efectividad que tiene el derecho penal para erradicarlas, reconociendo que por sí solo, el derecho penal no conseguirá extinguir la mutilación genital femenina. Por eso se duda de la eficacia del derecho penal para corregir o terminar con las desigualdades en que se encuentran determinados colectivos $^{42}$, en el caso de la mutilación genital femenina, las mujeres inmigrantes, y examinar los efectos y la utilidad de recurrir, en este caso concreto, al derecho penal, que desde hace un tiempo a esta parte, viene considerándose como el medio idóneo para luchar contra la discriminación de la mujer. Hay que tener en cuenta que en los casos de discriminación, es fácil la huida hacía el derecho penal, que en estos casos se reduce a ejercer una función simbólica ${ }^{43}$.

Se deben utilizar otros medios para erradicar estas prácticas, pues únicamente con el recurso al derecho penal no es suficiente, como se ha demostrado tanto a nivel nacional como internacional, ni es el mejor instrumento para luchar contra la mutilación genital, deben implementar programas culturales, sociales y de otro tipo como los desarrollados por ONGs y organismos internacionales.

\section{CONCLUSIONES}

El fenómeno de la inmigración ha tenido una clara influencia en la inclusión el ordenamiento penal, como constitutivas de delito, prácticas ajenas a nuestra realidad cultural, como ha ocurrido con la mutilación genital femenina, una práctica ancestral, desconocida en nuestro país hasta la llegada de inmigrantes pertenecientes a culturas donde forma parte de sus tradiciones culturales más arraigadas. Estas prácticas, fundamentadas en una concepción patriarcal de la sociedad, suponen un atentado a los derechos humanos de la mujer, a su integridad, libertad, e igualdad, y son una clara y genuina manifestación de violencia de género.

Nuestro ordenamiento jurídico incluye en la reforma penal de 2003 la mutilación genital femenina entre las lesiones graves, para luchar contra ella de forma más eficaz. A pesar de esta inclusión la

42 LAURENZO COPELLO, P., «La discriminación por razón de sexo en la legislación penal», en Jueces para la Democracia, 34, 1999, pág. 16.

${ }^{43}$ BERNAL DEL CASTILLO, J., La discriminación en el Derecho penal, Granada, 1998, pág. 34. 
persecución en nuestro país de este delito encontró un gran obstáculo, porque en muchos casos, las mutilaciones no se realizaban en territorio español sino en los lugares de origen de los inmigrantes, que aprovechaban los viajes a los lugares de origen para realizar la mutilación de las mujeres y sobre todo de las niñas. Para conseguir una mayor eficacia en la lucha contra la mutilación genital femenina,se amplio el principio de jurisdicción universal y se incluyo en el mismo el delito de mutilación genital femenina, de esta forma, se podrían juzgar en España las mutilaciones realizadas en el extranjero, siempre que los culpables estuvieran en nuestro país.

Está justificada la inclusión de este delito en el principio de justicia universal porque la mutilación genital femenina supone un atentado a los derechos humanos y una manifestación de la violencia de género. En este principio deberían haberse incluido todas las acciones que supongan una violencia de género, para conseguir mayor eficacia en la lucha contra estas prácticas.

El principio de jurisdicción universal se extiende a aquellos delitos que se consideran de interés para la comunidad internacional, como es el caso de la mutilación genital femenina, que constituye un grave atentado a los derechos humanos de la mujer,porque a pesar de que la Declaración Universal de los Derechos Humanos se extiende a todos los seres humanos por el hecho de serlo, algunos de estos derechos, tradicionalmente, se han visto vulnerados o ignorados en el caso de las mujeres. Es un interés prioritario para la comunidad internacional la defensa de la igualdad de los derechos humanos de las mujeres, para acabar con las mutilaciones genitales femeninas y todas las manifestaciones de la violencia de género. 